\title{
Isogenic Group B Streptococci Devoid of Capsular Polysaccharide or $\beta$-Hemolysin: Pulmonary Hemodynamic and Gas Exchange Effects during Bacteremia in Piglets
}

\author{
R. L. GIBSON, G. J. REDDING, W. E. TRUOG, W. R. HENDERSON, AND C. E. RUBENS \\ Department of Pediatrics, Divisions of Neonatal and Respiratory Diseases and Infectious Diseases, and \\ Department of Medicine, University of Washington School of Medicine, Seattle, Washington 98195
}

\begin{abstract}
Group B $\beta$-hemolytic streptococcus (GBS) causes thromboxane (Tx)-associated pulmonary hypertension and hypoxemia in neonatal animals and human infants. The components of GBS that induce these features of sepsis are incompletely characterized. The capsular polysaccharide has been implicated based on the effects of GBS extracts. We used isogenic mutants of a parent GBS strain $(\mathrm{COH} 31 \mathrm{r} / \mathrm{s})$ devoid of capsular polysaccharide or $\beta$ hemolysin to determine if these components caused the acute features of GBS bacteremia. In neonatal piglets, we observed a similar increase in pulmonary vascular resistance (PVR, $\mathrm{mm} \mathrm{Hg} / \mathrm{L} / \mathrm{min}$ ) during a $1 \mathrm{~h}$ infusion at $5 \times$ $10^{8}$ colony-forming unit $/ \mathrm{kg} / \mathrm{h}$ of $\mathrm{COH} 31 \mathrm{r} / \mathrm{s}(n=5,11.6$ \pm 1.4 to $67.1 \pm 17.9$ ), an isogenic GBS mutant devoid of type III CP $(n=5,12.5 \pm 1.4$ to $56.9 \pm 5.0)$, and an isogenic GBS mutant devoid of $\beta$-hemolysin $(n=4,11.0$ \pm 1.9 to $51.9 \pm 7.9$ ). All three GBS strains caused increases in blood $\mathrm{TxB}_{2}$ levels, mild arterial hypoxemia, mild reduction in mixed venous $\mathrm{PO}_{2}$, and a $30-40 \%$ reduction in cardiac output after a $1 \mathrm{~h}$ infusion. The Tx-synthase inhibitor, dazmegrel, completely reversed pulmonary hypertension, and partially reversed arterial hypoxemia and $\mathbf{T x B}_{2}$ levels to baseline values for all GBS strains. In six additional piglets, infusion of polystyrene beads of similar size to GBS at a dose of $5 \times 10^{8} \mathrm{beads} / \mathrm{kg} / \mathrm{h}$ caused no changes in gas exchange or blood $\mathbf{T x B}_{2}$ levels, but a mild increase in PVR $(13.3 \pm 2.0$ to $17.7 \pm 3.5)$. This suggests a nonspecific response to circulating particulates is not the major cause of the acute features of GBS bacteremia in piglets. We conclude that type III capsular polysaccharide and $\beta$-hemolysin are not essential for type III GBS to cause acute $\mathrm{Tx}$-associated pulmonary hypertension and hypoxemia in piglets. (Pediatr Res 26:241-245, 1989)
\end{abstract}

\section{Abbreviations}

cfu, colony forming unit

$\mathrm{CO}$, cardiac output

COH $31 \mathrm{r} / \mathrm{s}$, parent type III GBS strain

COH 31-15, GBS mutant devoid of capsular polysaccharide

COH 31C5, GBS mutant devoid of $\beta$-hemolysin

$\mathrm{CP}$, capsular polysaccharide

Received February 20, 1989; accepted May 8, 1989.

Correspondence Ronald L. Gibson, M.D., Ph.D., Department of Pediatrics, RD-20, University of Washington School of Medicine, Seattle, WA 98195.

R.L.G was supported in part by an American Lung Association Research Training Award, the American Lung Association of Washington, and a RJR Nabisco Research Scholar Award. G.J.R., W.E.T., and W.R.H. were supported in part by NIH Program Project HL 39157.
DAZ, dazmegrel

GBS, group B streptococcus

$\mathrm{P}_{\mathrm{pa}}$, pulmonary artery pressure

PS, polystyrene

$\mathbf{P}_{\text {sa }}$, systemic artery pressure

PVR, pulmonary vascular resistance

$P_{w}$, pulmonary capillary wedge pressure

$\mathrm{TxB}_{2}$, thromboxane $\mathrm{B}_{2}$

IV, intravenous

EU, endotoxin units

GBS, a common gram-positive pathogen in neonatal sepsis, is associated with significant morbidity and mortality in septic human newborns $(1,2)$. GBS is classified into serotypes by the type-specific capsular polysaccharide; type III GBS cause the majority of neonatal infections (1). GBS bacteremia in human newborns and neonatal animals causes hypoxemia, pulmonary hypertension, and reduced cardiac output (3-7), and these acute changes are associated with increased blood $\mathrm{TxB}_{2}$ levels (5-7). Gram-negative bacteremia causes similar features $(8,9)$, and the lipid A moiety of endotoxin is the bacterial component that induces arachidonic acid metabolites, hypoxemia, and pulmonary hypertension (10). Gram-positive organisms do not contain lipid $\mathrm{A}$, and a toxin common to all gram-positive organisms has not been identified. However, multiple gram-positive organisms, including type III GBS, Streptococcus faecalis, and Staphylococcus epidermidis, cause acute Tx-associated pulmonary hypertension and hypoxemia during IV infusion in piglets (11). It is uncertain if each these gram-positive organisms contains a specific toxin that mediates the acute effects of bacteremia.

The type III GBS components that induce Tx-associated pulmonary hypertension and hypoxemia are incompletely characterized. Two different polysaccharide toxins, including an extracellular mannan polysaccharide and a GBS extract containing type III capsular polysaccharide, are reported to cause these features of GBS sepsis $(12,13)$. The type III capsular polysaccharide extract in these studies also contained group B polysaccharide and protein (12), and therefore the role of capsular polysaccharide in stimulating the acute hemodynamic and gas exchange alterations during GBS bacteremia remains uncertain.

Isogenic mutants of type III GBS devoid of only type-specific capsular polysaccharide expression have been isolated by transposon insertional mutagenesis (14). These mutants provide a powerful alternative method to GBS extracts for studying the role of type III capsular polysaccharide during experimental GBS bacteremia. We hypothesized that a type III GBS mutant devoid of capsular polysaccharide would not stimulate acute Tx-associ- 
ated pulmonary hypertension and hypoxemia when infused in piglets. An isogenic mutant of type III GBS devoid of $\beta$-hemolysin was also used to test the role of $\beta$-hemolysin in the acute features of GBS bacteremia (15).

\section{MATERIALS AND METHODS}

Animal preparation. Twenty piglets, $16 \pm 3 \mathrm{~d}$ of age, and weighing $3.7 \pm 0.6 \mathrm{~kg}$ were anesthetized $(30 \mathrm{mg} / \mathrm{kg}$ pentobarbital IV), paralyzed $(0.3 \mathrm{mg} / \mathrm{kg}$ pancuronium bromide IV), anticoagulated with heparin (1000 IU IV), and mechanically ventilated via a tracheostomy tube with a large animal Harvard ventilator adjusted to deliver a tidal volume of $12 \pm 2 \mathrm{~mL} / \mathrm{kg}$ at a rate to maintain $\mathrm{PaCO}_{2}$ at $40 \pm 5 \mathrm{~mm} \mathrm{Hg}$ during baseline conditions. All animals were ventilated with room air throughout each experiment. As previously described (11), catheters were placed in 1 ) the left external jugular vein for infusion of bacteria, 2) the aorta to measure $\mathrm{P}_{\mathrm{sa}}$ and sample arterial blood for $\mathrm{pH}$, blood gas tensions, and $\mathrm{TxB}_{2}$ measurements, and 3) a branch of the left pulmonary artery ( $5 \mathrm{Fr}$ Swan-Ganz thermodilution catheter) to measure $\mathrm{P}_{\mathrm{pa}}$ and $\mathrm{P}_{\mathrm{w}}, \mathrm{CO}$ in triplicate by thermodilution using an Edwards 9520A cardiac output computer (Santa Ana, CA), and for sampling mixed venous blood. After instrumentation, anesthesia and muscle paralysis were maintained with pentobarbital ( $3 \mathrm{mg} / \mathrm{kg} \mathrm{IV} \mathrm{q} 1 \mathrm{~h})$ and pancuronium bromide $(0.3 \mathrm{mg} / \mathrm{kg} \mathrm{IV} \mathrm{q}$ $1 \mathrm{~h})$, respectively. The piglets received sigh breaths to $30 \mathrm{~cm} \mathrm{H}_{2} \mathrm{O}$ every $20 \mathrm{~min}$ to minimize spontaneous development of atelectasis. Vascular pressures were measured using Hewlett-Packard 1280 transducers (Hewlett-Packard Co., Palo Alto, CA) and were referenced to midchest. Core temperature was maintained at $38.5 \pm 0.5^{\circ} \mathrm{C}$ with an overhead radiant heat source.

$G B S$ strains and preparation. The parent GBS strain is a type III clinical isolate that is tetracycline sensitive, but made rifampin and streptomycin resistant $(\mathrm{COH} 31 \mathrm{r} / \mathrm{s})$. The isogenic mutants of type III GBS were derived previously from $\mathrm{COH} 31 \mathrm{r} / \mathrm{s}$ by transposon insertional mutagenesis $(14,15)$. Each GBS mutant tested is identical to the parent strain except for the absence of a specific bacterial component, and acquisition of tetracyclineresistance after transposon insertion. The GBS strain $\mathrm{COH} 31$ 15 is an isogenic mutant of the parent strain devoid of type III capsular polysaccharide. $\mathrm{COH}$ 31-15 contains no type III capsular polysaccharide on its surface based on a competitive ELISA assay or immune electron microscopy with type III GBS antiserum (14), but does express the group B polysaccharide. The GBS strain $\mathrm{COH} 31 \mathrm{C} 5$ is an isogenic mutant of the parent strain devoid of $\beta$-hemolysin (15), but expresses type III capsular polysaccharide and group B polysaccharide identical to the parent strain. The stability of the $\mathrm{COH} 31-15$ mutation is demonstrated by the absence of a detectable revertance rate after serial passage of $\mathrm{COH} 31-15$ on drug-free media or after isolation from infected animals (Rubens $\mathrm{C}$, unpublished observations), and the persistence of tetracycline-resistance during this study. The stability of the $\mathrm{COH} 31 \mathrm{C} 5$ mutation is supported by the blood cultures from each piglet in this study yielding non- $\beta$-hemolytic colonies. The culture conditions, mode of resuspension in sterile nonbacteriostatic saline, tests of culture purity, measurement of bacterial concentrations, and quantitative blood cultures were performed as described (11). The GBS suspensions for infusion into piglets contained $<0.03 \mathrm{EU} / \mathrm{mL}$ of endotoxin based on the limulus amebocyte lysate assay $(5 \mathrm{EU} / \mathrm{mL}=1 \mathrm{ng} / \mathrm{mL}$ ) (Associates of Cape Cod, Woods Hole, MA).

Polystyrene beads. Uniform polystyrene beads $2.355 \pm 0.026$ $\mu \mathrm{m}$ in diameter (Seradyn, Particle Technology Div., Indianapolis, IN) were pelleted at $25000 \times g$ and resuspended in $0.9 \%$ saline plus $0.02 \%$ Triton-X-100. The resuspended beads were probe sonicated at medium intensity for $20 \mathrm{~s}$, and then inspected under light microscopy, which demonstrated no aggregation. The concentration of beads in a 1:100 dilution of the resuspension was measured in duplicate using a hemocytometer.

$T \times B_{2}$ assays. Two-ml arterial blood samples were obtained under three experimental conditions for each protocol. The blood samples were drawn into cold inhibitor solution containing indomethacin and sodium EDTA, and centrifuged as previously described (6). The decanted plasma was frozen at $-70^{\circ} \mathrm{C}$ until a RIA for $\mathrm{TxB}_{2}$, the stable hydrolysis product of $\mathrm{TxA}_{2}$, was performed as described (6). $\mathrm{TxB}_{2}$ was assayed by measuring competitive inhibition of $\left[{ }^{3} \mathrm{H}\right] \mathrm{TXB}_{2}$ to rabbit anti- $\mathrm{TxB}_{2}$ binding as previously described (6). The average of duplicate assays was used to determine means for the different experimental conditions.

Experimental design. In each piglet infused with GBS, $\mathrm{P}_{\mathrm{pa}}, \mathrm{P}_{\mathrm{w}}$, $\mathrm{P}_{\mathrm{sa}}, \mathrm{CO}$, arterial and mixed venous gas tensions, arterial blood samples for measurement of $\mathrm{TxB}_{2}$, and quantitative blood cultures were obtained under three conditions: 1) before GBS infusion (PRE), 2) $60 \mathrm{~min}$ after the onset of the GBS infusion via a central venous catheter $(0.1-0.2 \mathrm{~mL} / \mathrm{min})$ at a dose of $5 \times$ $10^{8} \mathrm{cfu} / \mathrm{kg} / \mathrm{h}(60 \mathrm{~min})$, and 3) $90 \mathrm{~min}$ after the onset of the GBS infusion and $30 \mathrm{~min}$ after an IV infusion of $8 \mathrm{mg} / \mathrm{kg}$ of DAZ, a thromboxane synthase inhibitor (6). Five piglets received GBS strain $\mathrm{COH} 31 \mathrm{r} / \mathrm{s}$, five piglets received GBS strain $\mathrm{COH}$ 31-15 (devoid of capsular polysaccharide), and four piglets received GBS strain COH 31C5 (devoid of $\beta$-hemolysin). Dazmegrel (UK 38,435 kindly provided by R. Urguilla, Pfizer Laboratories, Groton, CT) was dissolved in $1.5 \mathrm{~mL}$ of $0.1 \mathrm{~N} \mathrm{NaOH}$ to which $0.9 \%$ saline was added to make a $7.5 \mathrm{~mL}$ solution.

Six piglets were infused with PS beads, similar in size to GBS, suspended in $0.9 \%$ saline plus $0.2 \%$ Triton-X-100 to serve as a particulate control. In parallel with the GBS experiments, the same measurements were obtained 1 ) before to PS bead infusion (PRE), 2) $60 \mathrm{~min}$ after the onset of $5 \times 10^{8}$ beads $/ \mathrm{kg} / \mathrm{h}(0.2-0.5$ $\mathrm{ml} / \mathrm{min}$ ), and 3) $90 \mathrm{~min}$ after the onset of bead infusion, and 30 min after DAZ administration. The infusion of $0.9 \%$ saline plus $0.02 \%$ Triton-X-100 alone at $1.0 \mathrm{~mL} / \mathrm{min}$ caused no significant changes in hemodynamic or gas exchange parameters.

Statistical analysis. Analysis of variance was used to compare the $1 \mathrm{~h}$ GBS or bead values between the four experimental groups; paired Student's $t$ tests were used to compare the $1 \mathrm{~h}$ GBS or DAZ values to PRE values for each experimental group (SPSS-PC + , Microsoft, Bellevue, WA). A $p$ value of $\leq 0.05$ was considered significant.

\section{RESULTS}

PVR significantly increased to a similar degree (4- to 6-fold) in piglets infused with either 1) the parent type III GBS strain $(\mathrm{COH} 31 \mathrm{r} / \mathrm{s}), 2)$ an isogenic GBS mutant devoid of type III capsular polysaccharide ( $\mathrm{COH} 31-15)$ or 3 ) an isogenic mutant devoid of $\beta$-hemolysin ( $\mathrm{COH} 31 \mathrm{C5}$ ) (Table 1). During the $1 \mathrm{~h}$ GBS infusion, $P_{p a}$ increased 3-fold, $P_{w}$ significantly increased, and CO decreased $30-40 \%$ for the three isogenic GBS strains (Table 1).

The three isogenic GBS strains caused a similar degree of arterial hypoxemia, and a similar decrease in mixed venous $\mathrm{PO}_{2}$ $1 \mathrm{~h}$ into the GBS infusion (Table 2). There were no significant changes in arterial $\mathrm{PCO}_{2}$. Although there were small but statistically significant reductions in arterial $\mathrm{pH}$ after $1 \mathrm{~h}$ of infusion of all GBS strains, mean values remained in the normal range for piglets (Table 2).

Arterial $\mathrm{TxB}_{2}$ levels significantly increased $1 \mathrm{~h}$ after the onset of bacterial infusion for all three GBS strains (Table 3). There were no statistically significant differences between the $60 \mathrm{~min}$ $\mathrm{TxB}_{2}$ levels for the three GBS strains. However, the COH $31 \mathrm{r} / \mathrm{s}$ $60 \mathrm{~min}$ TxB2 levels $(243,118,88,74$, and $143 \mathrm{pg} / 0.1 \mathrm{~mL})$ were more variable than the $\mathrm{COH} 31-15$ values $(60,67,60,70$, and $62 \mathrm{pg} / 0.1 \mathrm{~mL}$ ), and although there is no statistically significant differences between the two groups, the power of the test to demonstrate a difference is limited to $63 \%$. Thirty min after DAZ infusion, with ongoing GBS infusion, pulmonary hypertension was reversed and $\mathrm{TxB}_{2}$ levels were partially reversed to near preinfusion values for all GBS strains (Tables 1 and 3). Dazme- 
Table 1. Similar hemodynamic responses to three isogenic GBS strains in piglets*

\begin{tabular}{|c|c|c|c|c|}
\hline & $\begin{array}{c}\mathrm{P}_{\mathrm{pa}} \\
(\mathrm{mm} \mathrm{Hg})\end{array}$ & $\begin{array}{c}P_{w} \\
(m m H g)\end{array}$ & $\begin{array}{c}\text { C.O. } \\
\text { (L/min) }\end{array}$ & $\begin{array}{c}\text { PVR } \\
(\mathrm{mm} \mathrm{Hg} / \mathrm{L} / \mathrm{min})\end{array}$ \\
\hline \multicolumn{5}{|c|}{$\begin{array}{l}\mathrm{COH} 31 \mathrm{r} / \mathrm{s}(n=5) \\
\text { (parent) }\end{array}$} \\
\hline PRE & $14.2 \pm 1.1$ & $2.4 \pm 0.4$ & $1.04 \pm 0.10$ & $11.6 \pm 1.4$ \\
\hline $60 \mathrm{~min}$ & $+43.0 \pm 1.8$ & $\dagger 5.7 \pm 0.7$ & $\uparrow 0.66 \pm 0.13$ & $\dagger 67.1 \pm 17.9$ \\
\hline $\mathrm{DAZ}$ & $14.0 \pm 1.2$ & $2.4 \pm 0.5$ & $0.83 \pm 0.09$ & $13.7 \pm 2.0$ \\
\hline \multicolumn{5}{|c|}{$\begin{array}{c}\mathrm{COH} 31-15(n=5) \\
\text { (capsule) }\end{array}$} \\
\hline PRE & $14.4 \pm 0.8$ & $2.6 \pm 0.7$ & $0.98 \pm 0.08$ & $12.5 \pm 1.4$ \\
\hline $60 \mathrm{~min}$ & $\dagger 39.1 \pm 1.3$ & $\dagger 5.0 \pm 1.1$ & $\dagger 0.62 \pm 0.07$ & $\dagger 56.9 \pm 5.0$ \\
\hline DAZ & $16.2 \pm 1.0$ & $3.2 \pm 1.1$ & $0.84 \pm 0.06$ & $15.7 \pm 1.0$ \\
\hline \multicolumn{5}{|c|}{$\begin{array}{c}\mathrm{COH} 31 \mathrm{C} 5(n=4) \\
\text { (hemolysin) }\end{array}$} \\
\hline PRE & $12.9 \pm 1.0$ & $2.6 \pm 0.6$ & $0.95 \pm 0.04$ & $11.0 \pm 1.9$ \\
\hline $60 \mathrm{~min}$ & $+36.3 \pm 2.3$ & $\dagger 3.9 \pm 0.5$ & $\dagger 0.65 \pm 0.06$ & $\dagger 51.9 \pm 7.9$ \\
\hline DAZ & $12.0 \pm 0.9$ & $2.3 \pm 0.7$ & $0.86 \pm 0.04$ & $11.3 \pm 1.3$ \\
\hline \multicolumn{5}{|c|}{$\begin{array}{l}\text { Polystyrene beads } \\
\qquad(n=6)\end{array}$} \\
\hline PRE & $15.3 \pm 1.1$ & $3.8 \pm 0.3$ & $0.93 \pm 0.11$ & $13.3 \pm 2.0$ \\
\hline $60 \mathrm{~min}$ & $\dagger 18.0 \pm 1.5$ & $4.5 \pm 0.3$ & $0.85 \pm 0.11$ & $\dagger 17.7 \pm 3.5$ \\
\hline $\mathrm{DAZ}$ & $17.2 \pm 0.8$ & $4.5 \pm 0.5$ & $0.87 \pm 0.10$ & $15.4 \pm 1.9$ \\
\hline
\end{tabular}

* Values are expressed as mean \pm SEM. PRE, before GBS or PS bead infusion; 60 min, 60 min after the onset of the GBS or PS bead infusion; $\mathrm{DAZ}, 30 \mathrm{~min}$ after administration of DAZ with ongoing GBS or PS bead infusion.

$\dagger$ Denotes $p \leq 0.05$ compared to PRE value.

Table 2. Similar blood gas changes in response to three isogenic $G B S$ strains in piglets*

\begin{tabular}{|c|c|c|c|c|}
\hline & $\mathrm{pH}$ & $\begin{array}{c}\mathrm{PaCO}_{2} \\
(\mathrm{~mm} \mathrm{Hg})\end{array}$ & $\begin{array}{c}\mathrm{PaO}_{2} \\
(\mathrm{~mm} \mathrm{Hg})\end{array}$ & $\begin{array}{c}\mathrm{PvO}_{2} \\
(\mathrm{~mm} \mathrm{Hg})\end{array}$ \\
\hline \multicolumn{5}{|c|}{$\mathrm{COH} 31 \mathrm{r} / \mathrm{s}$ (parent) } \\
\hline PRE & $7.42 \pm 0.02$ & $39 \pm 2.0$ & $94 \pm 2.8$ & $47 \pm 1.4$ \\
\hline $60 \mathrm{~min}$ & $\dagger 7.36 \pm 0.01$ & $38 \pm 2.2$ & $\dagger 64 \pm 5.2$ & $\dagger 37 \pm 2.6$ \\
\hline $\mathrm{DAZ}$ & $7.39 \pm 0.02$ & $37 \pm 1.6$ & $78 \pm 2.0$ & $44 \pm 1.3$ \\
\hline \multicolumn{5}{|c|}{$\mathrm{COH} 31-15$ (capsule) } \\
\hline PRE & $7.45 \pm 0.01$ & $39 \pm 1.2$ & $92 \pm 4.0$ & $41 \pm 1.4$ \\
\hline $60 \mathrm{~min}$ & $\dagger 7.40 \pm 0.01$ & $40 \pm 1.2$ & $\dagger 71 \pm 5.5$ & $\dagger 31 \pm 1.0$ \\
\hline DAZ & $7.41 \pm 0.01$ & $40 \pm 1.1$ & $80 \pm 4.0$ & $38 \pm 2.0$ \\
\hline \multicolumn{5}{|c|}{$\mathrm{COH} 31 \mathrm{C} 5$ (hemolysin) } \\
\hline PRE & $7.42 \pm 0.02$ & $38 \pm 2.0$ & $95 \pm 2.5$ & $40 \pm 2.7$ \\
\hline $60 \mathrm{~min}$ & $\dagger 7.38 \pm 0.02$ & $41 \pm 1.7$ & $\dagger 66 \pm 3.0$ & $\dagger 31 \pm 4.0$ \\
\hline DAZ & $7.39 \pm 0.01$ & $40 \pm 1.6$ & $78 \pm 1.1$ & $36 \pm 4.2$ \\
\hline \multicolumn{5}{|c|}{ Polystyrene beads } \\
\hline PRE & $7.42 \pm 0.01$ & $38 \pm 1.2$ & $87 \pm 2.4$ & $42 \pm 0.7$ \\
\hline $60 \mathrm{~min}$ & $7.43 \pm 0.01$ & $39 \pm 0.5$ & $88 \pm 3.4$ & $42 \pm 1.0$ \\
\hline DAZ & $7.42 \pm 0.01$ & $40 \pm 1.2$ & $82 \pm 4.0$ & $41 \pm 1.0$ \\
\hline
\end{tabular}

$*$ Values are expressed as mean \pm SEM. PRE, before GBS or PS bead infusion; $60 \mathrm{~min}, 60 \mathrm{~min}$ after the onset of the GBS or PS bead infusion; $\mathrm{DAZ}, 30 \mathrm{~min}$ after administration of DAZ with ongoing GBS or PS bead infusion.

$\dagger$ Denotes $p \leq 0.05$ compared to PRE value.

grel administration also resulted in partial return to baseline values for $\mathrm{CO}, \mathrm{PaO}_{2}$, and $\mathrm{PvO}_{2}$ (Tables 1 and 2).

Polystyrene beads $(2.355 \mu \mathrm{m}$ in diameter $)$ of similar size to GBS were infused into piglets to test if the similar response to all three GBS strains was due to a nonspecific pulmonary vascular response to circulating particulates. The infusion of PS beads at $5 \times 10^{8}$ beads $/ \mathrm{kg} / \mathrm{h}$ caused mild, but consistent increases in Ppa
Table 3. Blood TXB levels $(\mathrm{pg} / 0.1 \mathrm{ml})$ increase during infusion of three isogenic GBS strains in piglets*

\begin{tabular}{lcccc}
\hline & $\begin{array}{c}\text { COH 31 r/s } \\
\text { (parent) }\end{array}$ & $\begin{array}{c}\text { COH 31-15 } \\
\text { (capsule) }\end{array}$ & $\begin{array}{c}\text { COH 31C5 } \\
\text { (hemolysin) }\end{array}$ & PS beads \\
\hline PRE & $<10$ & $<10$ & $17 \pm 2$ & $11 \pm 1$ \\
$60 \mathrm{~min}$ & $\dagger 133 \pm 30$ & $\dagger 64 \pm 5$ & $\dagger 71 \pm 6$ & $12 \pm 2$ \\
$\mathrm{DAZ}$ & $29 \pm 10$ & $30 \pm 4$ & $20 \pm 6$ & $<10$ \\
\hline
\end{tabular}

* Arterial blood was sampled under each of three experimental conditions and $\mathrm{TxB}_{2}$ was assayed in duplicate by RIA as described in methods. Values are expressed as mean \pm SEM. PRE, before GBS or PS bead infusion; $60 \mathrm{~min}, 60 \mathrm{~min}$ after the onset of the GBS or PS bead infusion; DAZ, 30 min after administration of DAZ with ongoing GBS or PS bead infusion.

$\dagger$ Denotes $p<0.05$ compared to PRE value.

and PVR, with no changes in cardiac output or gas exchange values (Tables 1 and 2). The degree of pulmonary vasoconstriction was significantly less in the piglets infused with PS beads compared to the three GBS strains (Table 1). In addition, arterial $\mathrm{TxB}_{2}$ levels were not increased during PS bead infusion (Table 3).

Quantitative arterial blood cultures $1 \mathrm{~h}$ after the onset of GBS infusion found statistically similar colony counts for $\mathrm{COH} 31 \mathrm{r} /$ $\mathrm{s}\left(1.7 \pm 0.5 \times 10^{4} \mathrm{cfu} / \mathrm{mL}\right), \mathrm{COH} 31-15\left(3.5 \pm 2.3 \times 10^{4} \mathrm{cfu} /\right.$ $\mathrm{mL})$, and $\mathrm{COH} 31 \mathrm{C5}\left(10.5 \pm 6.6 \times 10^{4}\right.$ non- $\beta$-hemolytic cfu/ $\mathrm{mL})$. There were no significant changes in blood colony counts after DAZ for all three GBS strains. All blood cultures were sterile before experimental GBS infusion.

\section{DISCUSSION}

An isogenic mutant of type III GBS devoid of only the type III capsular polysaccharide ( $\mathrm{COH} 31-15)$ causes a similar degree of acute Tx-associated pulmonary hypertension, hypoxemia, and reduction in CO compared to the parent type III GBS strain $(\mathrm{COH} 31 \mathrm{r} / \mathrm{s})$ in neonatal piglets. The increase in PVR, and in part the increase in $\mathrm{TxB}_{2}$ levels induced by each GBS strain is 
reversed by DAZ. These results provide evidence that type III capsular polysaccharide is not essential for type III GBS to induce thromboxane synthesis, pulmonary hypertension, hypoxemia, or reduce $\mathrm{CO}$ during the acute phase $(<1 \mathrm{~h})$ of type III GBS bacteremia in piglets. We are greater than $80 \%$ confident that we could have detected a $6 \mathrm{mmHg}$ difference in the $1 \mathrm{~h} \mathrm{P}_{\mathrm{pa}}$ values for GBS $31 \mathrm{r} / \mathrm{s}$ and GBS 31-15. The similar results, including TxB2 levels, with $\mathrm{COH} 31-15$ and the $\mathrm{COH} 31 \mathrm{C} 5$ strain, which lacks $\beta$-hemolysin but contains the same amount of capsular polysaccharide as the parent GBS strain, provides further evidence that capsular polysaccharide is not essential for the acute effects of GBS sepsis. There is a statistically insignificant trend toward increased $60 \mathrm{~min} \mathrm{TxB} 2$ levels for $\mathrm{COH} 31 \mathrm{r} / \mathrm{s}$ compared to $\mathrm{COH} 31-15$, but due to the limited power of the test we cannot exclude the possibility that the presence of type III capsular polysaccharide may influence the degree of TxB2 synthesis in piglets infused with GBS. The type III GBS strain $\mathrm{COH}-1$ (nonisogenic to $\mathrm{COH} 31 \mathrm{r} / \mathrm{s}$ ), contains approximately 10 -fold more type III capsular polysaccharide than $\mathrm{COH} 31 \mathrm{r} / \mathrm{s}$ (Wessels M, Rubens C, unpublished data), and causes a similar degree of pulmonary hypertension and increased $\mathrm{TxB}_{2}$ levels as $\mathrm{COH} 31 \mathrm{r} / \mathrm{s}$ in piglets (11). This is corroborating evidence that type III capsular polysaccharide is not essential for the acute effects of type III GBS bacteremia in piglets. However, type III capsular polysaccharide may play a role in the late responses $(\geq 2$ h) of GBS bacteremia, as extracts of type III GBS containing capsular polysaccharide can promote neutrophil adherence to endothelium in vitro (16), and induce lung inflammation when infused into sheep (17). Our experimental design did not evaluate this role of capsular polysaccharide in piglets.

Hemolysins are important virulence factors for some grampositive neonatal pathogens, such as Listeria monocytogenes and $S$. faecalis $(18,19)$. However, the $\beta$-hemolysin of GBS is not a virulence factor in a neonatal rat model of sepsis based on the similar $\mathrm{LD}_{50}$ doses for $\mathrm{COH} 31 \mathrm{r} / \mathrm{s}$ and $\mathrm{COH} 31 \mathrm{C} 5$ (15). Our results with the isogenic mutant devoid of $\beta$-hemolysin $(\mathrm{COH}$ $31 \mathrm{C5})$ provide evidence that $\beta$-hemolysin is not necessary to induce acute Tx-associated pulmonary hypertension and hypoxemia during GBS bacteremia in piglets. Although $1-2 \%$ of GBS isolated from infected human newborns are non $\beta$-hemolytic (15), there are no published data comparing the clinical features of non $\beta$-hemolytic strains to $\beta$-hemolytic strains to corroborate our findings.

An extract of GBS containing type III capsular polysaccharide induces acute pulmonary hypertension, hypoxemia, and hypotension during bolus infusions in sheep (12). These data differ from our results regarding the role of type III capsular polysaccharide in GBS bacteremia. Perhaps multiple GBS components are capable of inducing these features, but the reason for this discrepancy is uncertain. First, although type III capsular polysaccharide is not essential to induce the acute features of GBS bacteremia, the infusion of capsular polysaccharide may cause hemodynamic and gas exchange alterations in a dose-dependent manner. GBS strain COH $31 \mathrm{r} / \mathrm{s}$ contains $3 \mu \mathrm{g}$ of type III capsular polysaccharide per $5 \times 10^{8}$ bacteria (Wessels M, Rubens C, unpublished data), and therefore we estimate piglets in our study were infused with the equivalent of $3 \mu \mathrm{g} / \mathrm{kg} / \mathrm{h}$ of capsular polysaccharide. This is a 100 to 200 -fold lower dose of capsular polysaccharide than the dose of GBS capsular polysaccharide extract that caused pulmonary vasoconstriction when infused into sheep (12). Second, the group B polysaccharide or protein components that contaminated the GBS extract may have caused the hemodynamic and gas exchange alterations. There are no data for the group B polysaccharide, but group B streptococcal peptidoglycan can induce complement consumption and inflammation in other animal models (20). Finally, the possible fragmentation and denaturation of the complex carbohydrate structure of the type III antigen during extraction may alter its biologic activity.
Polystyrene beads were infused in piglets to test if a nonspecific pulmonary vascular response to circulating particulates could explain why the three GBS strains caused similar hemodynamic and gas exchange alterations. Several species, including swine, contain pulmonary intravascular macrophages that are capable of ingesting circulating bacteria or particulates (21-23). Pulmonary intravascular macrophages can synthesize on array of arachidonic acid metabolites, including $\mathrm{TxB}_{2}$, and therefore may play a role in the cardiopulmonary responses to bacteremia or circulating particulates $(24,25)$. The minimal hemodynamic response in piglets infused with polystyrene beads $\left(5 \times 10^{8}\right.$ beads/ $\mathrm{kg} / \mathrm{h}$ ) suggest that a nonspecific pulmonary vascular response to circulating particulates is not the major cause of the acute features of GBS bacteremia in piglets.

Type III GBS capsular polysaccharide is a major virulence factor, and allows GBS to evade local or systemic phagocytic host defenses (14). Several studies indicate antitype III antibodies are protective against GBS infection in animal models and human infants (26-28). However, our data suggest that once host defenses are overwhelmed and significant bacteremia occurs, the type III capsular polysaccharide is not essential for inducing acute hemodynamic and gas exchange abnormalities of GBS sepsis.

Acknowledgments. The authors appreciated the technical assistance of Richard Tuck, James Jordan, and Paul Lehman, and the assistance of Elizabeth Lien and Laura Heggen in the preparation of GBS. The authors thank JoAnn Jarrett for secretarial assistance in preparing the manuscript.

\section{REFERENCES}

1. Baker CJ 1977 Summary of the workshop on perinatal infection due to group B streptococcus. J Infect Dis 136:137-151

2. Anthony BF 1985 Epidemiology of GBS in man. Antibiot Chemother 35:10 16

3. Rojas J, Green RS, Hellerqvist CG, Olegard R, Brigham KL, Stahlman MT 1981 Studies on group B $\beta$-hemolytic streptococcus. II. Effects on pulmonary hemodynamics and vascular permeability in unanesthetized sheep. Pediatr Res 15:899-904

4. Sorensen GK, Redding GJ, Truog WE 1985 Mechanisms of pulmonary gas exchange abnormalities during experimental group B streptococcus infusion. Pediatr Res 19:922-926

5. Runkle B, Goldberg RN, Streitfeld MM, Clark MR, Buron E, Setzer ES, Bancalari E 1984 Cardiovascular changes in group B streptococcal sepsis in the piglet: response to indomethacin and the relationship to prostacyclin and thromboxane A2. Pediatr Res 18:874-878

6. Truog WE, Sorensen GK, Standaert TA, Redding GJ 1986 Effects of the thromboxane synthase inhibitor, dazmegrel (UK 38,485), on pulmonary gas exchange and hemodynamics in neonatal sepsis. Pediatr Res 20:481-486.

7. Hammerman C, Lass N, Strates E, Komar K, Bui KC 1987 Prostanoids in neonates with persistent pulmonary hypertension. J Pediatr 110:470-472

8. Hales CA, Sonne L, Peterson M, Miller M, Watkins WD 1981 Role of thromboxane and prostacyclin in pulmonary vasomotor changes after endotoxin in dogs. J Clin Invest 68:497-505

9. Slotman GJ, Quinn JV, Burchard KW, Gann DS 1985 Thromboxane, prostacyclin, and the hemodynamic effects of graded bacteremic shock. Circ Shock 16:395-404

10. Burhop KE, Proctor RA, Raetz CRH, Will JA 1987 Pulmonary pressor responses in sheep to chemically defined precursors of $E$. coli endotoxin. $J$ Appl Physiol 62:1141-1149

11. Gibson RL, Troug WE, Redding GJ 1988 Thromboxane-associated pulmonary hypertension during three types of gram-positive bacteremia in piglets. Pediatr Res 23:553-556

12. Hemming VG, O'Brien WF, Fischer GW, Golden SM, Nobel SF 1984 Studies of short-term pulmonary and peripheral vascular responses induced in oophorectomized sheep by infusion of a group B streptococcal extract. Pediatr Res 18:266-269.

13. Hellerqvist CG, Sundell H, Gettins P 1987 Molecular basis for group B $\beta$ hemolytic streptococcal disease. Proc Natl Acad Sci USA 84:51-55

14. Rubens CE, Wessels MR, Heggen LM, Kasper DL 1987 Transposon mutagenesis of type III group B streptococcus: correlation of capsule expression with virulence. Proc Natl Acad Sci USA 84:7208-7212

15. Weiser JN, Rubens CE 1987 Transposon mutagenesis of group B streptococcus $\beta$-hemolysin biosynthesis. Infect Immun 55:2314-2316

16. McFall TL, Zimmerman GA, Augustine NH, Hill NR 1987 Effect of group B streptococcal type-specific antigen on polymorphonuclear leukocyte function and polymorphonuclear-endothelial interaction. Pediatr Res 21:517-523 
17. Olson TA, Fischer GW, Hemming VG, O'Brien WF, Golden SM, Maybee DA 1987 A group B streptococcal extract reduces neutrophil counts and induces neutrophil aggregation. Pediatr Res 21:326-330

18. Gaillard JL, Berche P, Sansonetti P 1986 Transposon mutagenesis as a tool to study the role of hemolysin in the virulence of Listeria monocytogenes. Infect Immun 52:50-55

19. Ike Y, Hashimoto H, Clewell 1984 Hemolysin of Streptococcus faecalis subspecies zymogenes contributes to virulence in mice. Infect Immun 45:528 530

20. Spitznagel JK, Goodrum KJ, Warejcka DJ, Weaver JL, Miller HL, Babcock L 1986 Modulation of complement fixation and the phlogistic capacity of group A, B, and D streptococci by human lyzozyme on their cell walls. Infect Immun 52:803-811

21. Warner AE, Molina RM, Brian JD 1987 Uptake of bloodborne bacteria by pulmonary intravascular macrophages and consequent inflammatory responses in sheep. Am Rev Respir Dis 136:683-690

22. Crocker SH, Lowery BD, Eddy DO, Wismar BL, Buesching WJ, Obenauf RN 1981 Pulmonary clearance of blood-borne bacteria. Surg Gynecol Obstet
153:845-851

23. Winkler GC, Cheville NF 1985 Monocytic origin and postnasal mitosis of intravascular macrophages in the porcine lung. J Leukocyte Biol 38:471480

24. Bertram TA, Overby LH, Danilowicz R, Eling TE, Brody AR 1988 Pulmonary intravascular macrophages metabolize arachidonic acid in vitro: comparison with alveolar macrophages. Am Rev Respir Dis 138:936-944

25. Miyamoto K, Schultz E, Heath T, Mitchell MD, Albertine KH, Staub NC 1988 Pulmonary intravascular macrophages and hemodynamic effects of liposomes in sheep. J Appl Physiol 64:1143-1152

26. Baltimore RS, Kasper DL, Vecchitto J 1979 Mouse protection test for group B streptococcus type III. J Infect Dis 140:81-88

27. Edwards MS, Baker CJ, Kasper DL 1979 Opsonic specificity of human antibody to the type III polysaccharide of group B streptococcus. J Infect Dis 140:1004-1008

28. Baker CJ, Kasper DL 1976 Correlation of maternal antibody deficiency with susceptibility to neonatal group B streptococcal infection. N Engl J Med 294:753-756 